\title{
Planning and Animal Welfare Law: Considering Why Planning Authorities in the Republic of Ireland Should have Regard to Animal Welfare Laws as Part of the Planning Process
}

\section{Michelle Strauss ${ }^{1}$ (D)}

Published online: 26 May 2020

(c) Springer Nature B.V. 2020

\begin{abstract}
Animal welfare legislation routinely places obligations on owners of animals to take action to ensure that the welfare of the animal(s) is protected. Such legislation often requires animals to be sheltered by appropriate housing. Where facilities are built to provide animal housing it may be necessary to seek planning permission for the development, this is particularly an issue in relation to commercial facilities. The general approach of planning authorities in the Republic of Ireland is not to have regard to animal welfare matters at the planning stage. With reference to commercial dog breeding this paper considers the implications of the failure to have regard to animal welfare legislation during the planning process and the impact this can have on both animal welfare, but also the risks such an approach poses to the environment and public health.
\end{abstract}

Keywords Animal law · Planning law $\cdot$ Environment $\cdot$ Pollution · Ireland · Dog breeding

\section{Introduction}

The adequate housing of animals is frequently an issue that arises in relation to animal welfare. It is important to ensure from a welfare perspective that both an animal's physical and mental needs are considered when designing such housing. Where animals are confined to facilities for the greater part of their day the importance of these issues becomes more acute. For those concerned with protecting the needs of animals in such situations, animal welfare laws assist to ensure minimum standards are maintained. The difficulty however with animal welfare laws is that

Michelle Strauss

michellekstrauss@gmail.com

1 London, UK 
they tend to operate reactively, addressing welfare breaches when they arise. In the context of animal housing there exists the possibility to take a proactive approach to welfare matters by considering animal welfare laws, alongside planning laws when assessing planning applications for facilities that house animals. The advantage of such an approach is that it can work to address many of the environmental and public health issues that planning law seeks to control, whilst at the same time mitigate welfare issues that can arise as a consequence of poor housing facilities.

This article focusses on the housing of dogs in commercial dog breeding establishments in the Republic of Ireland (ROI). Generally, such facilities operate with low staff to dog ratios and consequently dogs are kept in kennelling facilities for most of the day. Therefore, the proper design of these facilities is essential to the welfare of the animals, but also, as will be discussed in this article, to the environment and to public health. To ensure that a breeding facility operates in a manner that does not pose a threat to the health of animals, humans, and the environment there are certain minimum operational and construction requirements that need to be met. It is here that planning laws can work to enable these objectives to be realised by requiring construction matters that impact on welfare to be addressed during the planning application phase.

However, in the ROI the planning application process does not give consideration to animal welfare laws. To illustrate the problems inherent in such an approach, this article considers the intersection of animal welfare and planning legislation in relation to one aspect of commercial dog breeding, the generation and disposal of wastewater. The paper will consider how this issue was dealt with in the ROI in a planning application by a large-scale commercial dog breeder. The discussion relating to the case study will consider how the failure to have regard to animal welfare laws at the planning application stage not only risks jeopardising animal welfare but it potentially also risks undermines the objectives of planning and environmental legislation.

\section{Animal Welfare in Commercial Dog Breeding Establishments}

Keeping animals in housing facilities for the purposes of pursuing an economic activity such as breeding, can present welfare issues. The driver behind commercial breeding is to generate income and consequently this is often prioritised over the welfare of the animals housed within the facility. McMillan notes that Commercial Breeding Establishments are often characterised by,

...large numbers of dogs, maximal efficiency of space by housing dogs in or near the minimum space permitted by law, breeding dogs spend their entire lives in their cages or runs, group and solitary housing... minimal-to-no positive human interaction/companionship, and inadequate healthcare (McMillan 2017, p. 15)

These conditions give rise to two broad welfare concerns; the first is that the confinement and husbandry of the dogs can lead to behavioural and psychological 
stress. One of the consequences of this stress is that it can in turn have an impact on a dog's physical wellbeing. The kennelling of dogs in commercial breeding facilities can be a stressor as it creates an unnatural environment. Hurt notes,

The kennel environment by default puts dogs in a form of confinement, which dogs have not been selected for. This suggests it contradicts some of the natural motivations of dogs... The lack of control and increased boredom can create chronic distress and compromised welfare (Hurt 2016, p. 29).

Hurt explains how chronic distress can affects a dog's immune system and can lead to a decreased ability to fight off infection. The group environment exacerbates the problem as studies have demonstrated that there is a higher risk of the spread of disease where dogs are kept in group settings (Stull and O'Quin 2016, p. 621). As is the purpose of these breeding facilities, there are often significant numbers of puppies within the facilities. As puppies have developing immune systems they are particularly susceptible to contracting diseases, especially when kept in large groups (Clarebout and Casaert 2009). The evidence therefore appears to indicate that commercial breeding establishments create an environment that increases the likelihood of dogs within them to become ill and enable diseases to spread more easily. The predisposition of dogs to contract and spread disease in these facilities is a welfare concern.

The incidence of illness in commercial breeding facilities necessarily raises the issue of the hygiene standards in these establishments. Poor hygiene would in itself be a welfare concern, but the issue is more acute in dog breeding establishments for the reasons detailed above.

The animal welfare legislation in ROI does require operators to ensure that animals do not suffer and that the housing they are kept in is suitable and is not the cause of, or contributes to, any suffering. In respect of dog breeding establishments, the subordinate legislation ${ }^{1}$ regulates the construction and day to day functioning of commercial dog breeding facilities, mandating that certain activities must be undertaken to ensure that hygiene is maintained.

To expand this point, it is helpful to first detail the scope and specific provisions of the relevant animal welfare and planning legislation.

\section{Animal Welfare Legislation}

The Animal Health and Welfare Act 2013 ("AHWA") is the primary piece of legislation that provides protections to all "protected animals". "Protected animals" are defined as animals kept for farming, recreational, domestic, or sporting purposes, or those animals in the possession or control of a person whether permanently or on a temporary basis. ${ }^{2}$ The AWHA places obligations on those in charge of these animals to ensure that the animal is kept and treated in a manner that safeguards its health

\footnotetext{
1 The Dog Breeding Establishment Guidelines 2018.

2 AHWA s2(1).
} 
and welfare ${ }^{3}$ does not threaten the health and welfare of other animals, ${ }^{4}$ and that the buildings or structures in which the animal(s) are maintained are such that they do not cause injury or unnecessary suffering. 5,6

Dog breeding ${ }^{7}$ is regulated in the ROI by the Dog Breeding Establishment Act 2010 ("DBEA") and the subordinate legislation, the Dog Breeding Establishment Guidelines 2018 ("DBEG"). The DBEA applies to establishments that keep six or more bitches over the age of 6 months and are capable of breeding. ${ }^{8}$

The DBEA sets out the obligations operators of Dog Breeding Establishments (DBE) must meet as regard the care and housing of $\operatorname{dogs}^{9}$ and this is expanded upon in the DBEG. For example, the DBEA requires that dogs should have suitable accommodation and the DBEG provides greater detail in setting out the minimum requirements in relation to kennel sizes and construction.

For the purposes of this paper, the DBEG in force at the time was the 2011 version ${ }^{10}$ which required the following of operators:

- Protect the dogs from disease, distress, injury, fear, and pain ${ }^{11}$;

- Maintain the hygiene of the breeding premises and the health of the dogs held ${ }^{12}$;

- To facilitate the cleaning and disinfection of dog kennels, housing and exercise areas should be kept clean and maintained in a good state of repair ${ }^{13}$;

- Establishment to be constructed such that all waste, including washings, urine and faeces is managed by a suitable waste, drainage, storage, and disposal system $^{14}$;

- All waste to be collected and stored in suitable closed, lidded, leakproof containers held in a dedicated waste storage area. Waste removal or storage not to be a source of nuisance or public health risk $^{15}$;

- Grooming to be at least a minimum standard of care required for that breed. Coats should not be left unduly dirty, tangled, or unkempt ${ }^{16}$;

\footnotetext{
3 AHWA s11(1)(a)(i).

4 AHWA s11(1)(a)(ii).

5 AWHA s11(1)(b).

6 The above requirements are however qualified by the provision that the extent to which protections are required under this act are determined by having regard to the "animal's nature, type, species, breed, development, adaptation, domestication, physiological and behavioural needs and environment, and in accordance with established experience and scientific knowledge...".

7 The DBEA does not cover greyhounds. The keeping and breeding of Greyhounds is covered by the Welfare of Greyhounds Act 2011.

8 DBEA $s 2$.

9 DBEA 15.

10 These can be accessed: https://assets.gov.ie/3266/231118162555-f3c4db3db176435fa0bc2645d6e926 d2.pdf

11 DBEG(2011) 1.1.5-Part 1.

12 DBEG(2011) 1.1.6-Part 1.

13 DBEG(2011) 3.1.1-Part 1.

14 DBEG(2011) 3.3.1-Part 1.

15 DBEG(2011) 3.3.2-Part 1.

16 DBEG(2011) 3.1-Part 2.
} 
- Ensure all reasonable measures are taken as regard biosecurity to prevent and control the spread of infectious disease ${ }^{17}$; and

- Kennels and associated housing and exercise areas should be cleaned and disinfected as appropriate, and on a risk basis e.g. before new dogs or puppies are introduced or after an outbreak of infectious disease. ${ }^{18}$

Operators of DBEs must ensure that welfare is protected by adherence to the DBEA and DBEG. ${ }^{19}$ Where an operator is found to have inadequate facilities and/or processes that breach the legislation, he/she may be liable to fines or prosecution. As the studies above detail, the adequate cleaning of DBEs is essential to avoid disease. The physical and operational requirements in the DBEG have a direct bearing on waste generation as the cleaning process requires water and produces wastewater. Kennels in dog breeding establishments are usually hosed down to keep them clean. The cleaning water in turn is contaminated with by-products from the dogs such as faeces, urine and fluids produced during the process of birth and whelping. The water used in cleaning becomes wastewater.

The generation of wastewater is therefore both a welfare issue and a planning issue. It is a welfare issue because the amount and frequency of wastewater generation is a matter that goes directly to the cleanliness of a breeding facility. It is also a planning issue because the wastewater that the operators are obliged to generate under the DBEA and DBEG, must be disposed of.

\section{Planning Legislation}

Planning and environmental legislation is concerned with the proper use of land which extends to considering the generation and disposal of waste. A facility that is operating in compliance with the law will by necessity produce wastewater as a consequence of cleaning and in turn this substance must be disposed of in accordance with planning laws. If welfare considerations are not addressed at the planning stage and proper provision is not made to keep the facilities hygienic, then there runs the risk that planning authorities are allowing facilities to be built that when operational may breach welfare laws, or alternatively present threats to the environment that were not considered at the planning stage. Therefore, the contention is that for the objectives of both legislative frameworks to be achieved, animal welfare and planning law should be considered in tandem at the planning application stage.

Planning legislation has been consolidated in the Planning and Development Act ("PDA") 2000 (as amended) and forms the foundation for planning in Ireland. The legislation spans several planning related matters and transposes many of European Union directives relating to the environment. For the purposes of this paper the most

\footnotetext{
17 DBEG(2011) 3.6-Part 2.

18 DBEG(2011) 4.3-Part 2.

19 The predominant concern of this legislation is the welfare of the dogs, however it worth noting that requirements relating to hygiene and waste disposal are also directed towards preventing disease in both animals (outside the facility) and humans e.g. DBEG para 3.7.
} 
relevant aspect of the PDA is Part III of the Act that relates to the control of development. Broadly the PDA requires developments to obtain planning permission. ${ }^{20}$ Part of this process of seeking planning permission is to ensure that development is carried out in a proportionate way and due consideration is given to the effects of both the construction and any activities undertaken in the development once constructed. Underlying this legislative framework is an ethos of sustainability, which amongst other issues requires development to be strategic, of quality and to have regard for the environment. These aspects are key in deciding whether to grant permission, and whether any conditions should be imposed on such development. The phrase "sustainable development" used in the long title and throughout the PDA was deliberately not defined, as the responsible Minister at the time wished the concept to be dynamic, all embracing and capable of evolving (Grist 2012, p. 8).

Matters relating to proper planning and development are not confined to effects on the physical environment, but also cover matters relating to the impact that a development has on people (Gore-Grimes 2011, p. 703). This will necessarily cover public health and safety issues as was confirmed in the Supreme Court decision of Keane v An Bord Pleanála [1998] 2 ILRM 401.

Environmental protections are set out in several different pieces of legislation and regulated by different bodies such as the Environmental Protection Authority ${ }^{21}$ and the Department of Agriculture, Food and the Marine. ${ }^{22}$

\section{The Reason Why Wastewater from DBEs is a Planning Concern}

DBEs pose significant threats to the environment and public health. ${ }^{23}$ The degree to which this waste will be infectious depends to an extent on the health of the dogs and the preventative treatments (e.g. worming treatments) implemented by the operators of the breeding establishment, but the prevalence of disease will also be determined by the hygiene standards of the facility. Dogs are considered to be a "major reservoir for zoonotic infections" and that whilst "most of the viral and bacterial infections are transmitted from dogs to humans by dog bite... other infections caused by protozoa have a fecal oral transmission" (Namazi 2015). When dogs are infected with pathogens, these can often be found in their faeces (Namazi 2015; Towsey 2010).

\footnotetext{
${ }^{20}$ PDA s32, although some development is exempted as detailed in s4(1). However, if it is determined that an Environmental Impact Assessment or Appropriate Assessment then specific steps need to be taken.

21 The Environmental Protection Agency (EPA) carries out a wide range of functions. In relation to planning matters the EPA has responsibility for monitoring industrial activities and the discharge of pollution (Grist 2012, p. 169). For example, under the Local Government Water Pollution Act 1977 and 1990 the EPA regulates the discharge of trade effluent and requires such activities to be licensed.

22 For example the disposal of substances considered to be animal by-products is regulated by the European Union (Animal By-Products) Regulations 2014. Oversite of this legislation falls predominately to the Department of Agriculture, Food and the Marine (Department of Agriculture Food and the Marine n.d.).

23 This issue has also been considered in relation to the environmental effect of puppy mills in the United States (Towsey 2010).
} 
As was noted earlier in this paper, DBEs present an environment where disease is more likely to occur and where it does may spread more easily due to environmental stressors and the close confines in which the dogs are kept. Thorough cleaning regimes in DBEs can assist in preventing dogs from being infected by and spreading pathogens (Dendoncker 2018). As the process of cleaning DBEs usually involves hosing down the facilities, the resulting wastewater is likely to be contaminated by faeces. Consequently, in facilities where hygiene is compromised it is probable that there will be pathogens in wastewater. Parasites that infect dogs such as Toxocariasis and Cryptosporidium can survive in soil for months (Mirza 2012) and can prove resistant to disinfectants (Dupont and Butaye 2013; Towsey 2010). If this wastewater were to leach in waterways or private wells ${ }^{24}$ or be disposed of on land that is used for production of food or soil with which humans come into contact, it may pose a threat to human health.

Dog waste may also contain parasites that are harmful for livestock. Neospora caninum (Dubey 2003), Sarcocystosis (Centre for Food Security and Public Health 2005) and Echinococcosis (Centers for Disease Control and Prevention 2019) are diseases that affect cows and sheep and for which dogs are a host. These diseases can cause organ damage, abortions and in severe cases lead to death. Similarly some of the diseases found in dogs can also be transmissible to wildlife and can have devastating effects on these populations (Gondim 2004, Lafferty 2002, p. 595; Deem 2001).

Wastewater may also present an environmental hazard due to the relatively high levels of Nitrogen present in dog faeces. By way of comparison dog faeces contains $40 \%$ more Nitrogen than wet cattle manure (Patterson 2007, p. 238). If wastewater from dog faeces is to be discharged into the natural environment consideration should be given to the nutrient levels present as excess Nitrogen in the natural environment is linked to the eutrophication of waterways (Chislock and Doster 2013). This can have serious effects on the quality and viability of a water source. It is accepted that the severity of the threat posed to the environment in this respect is not linked to the welfare conditions in a breeding establishment. However, the impact of dog faeces on the natural environment becomes more acute where facilities house large numbers of dogs.

Yet, despite the potential hazards that the wastewater from DBE's poses to public health and the environment, the issues surrounding the production and discharge of wastewater from DBEs is given little consideration because many of the activities generating wastewater arise within the context of animal welfare law. Animal welfare matters are often not regarded as relevant planning consideration by planning authorities. The rationale for this approach is generally that animal welfare matters fall to be addressed by animal welfare laws once a facility is operational. ${ }^{25}$ This approach to planning matters in ROI is consistent with that taken in

\footnotetext{
24 "Sil cover can provide protection for the water in your well but if it shallow your well may be vulnerable to contamination. Polluting activities such as... land-spreading of slurry ... may pose a risk to the water in your well" (Environmental Protection Authority n.d.).

25 See comments by the Planning Authority in the case study below.
} 
other jurisdictions such as New Zealand (Rego 2017, p. 23), Australia (ABC News 2016) and the United Kingdom ${ }^{26}$ (Planning Committee Report-Lafford 2020) (Compassion in World Farming n.d.). Deciding planning permissions on this basis is problematic as it overlooks the reality that animal welfare legislation may regulate aspects of the construction and day to day functioning of developments and this may have an impact on matters that relate to planning.

The case study below provides an example of how the preclusion of consideration of animal welfare matters at a planning stage can undermine the objectives of planning law.

\section{Case Study: Planning Application for DBE to House 350 Dogs in County Cavan}

In 2016 a large-scale commercial dog breeder in County Cavan ${ }^{27}$ (the Cavan Application) sought retention planning permission for a breeding establishment to house 350 adult dogs. The Planning Authority at Cavan County Council approved the permission and, of significance for this paper, the proposals relating to wastewater. ${ }^{28}$ Objections were raised in respect of the application that were premised on animal welfare grounds. The position of Cavan County Council Planning Authority was that animal welfare issues were not relevant considerations at the planning stage:

\footnotetext{
26 A Committee report responding to objection raised to a pig fattening unit in Lincoln set out, "It is commonly accepted that animal welfare is not a material planning consideration, and as such Members are advised to assign extremely limited, if any, weight to it in the consideration of this application. The non-materiality of animal welfare was confirmed in correspondence between Officers and the Department of the Environment, Food and Rural Affairs (DEFRA) and the Department for Communities and the Local Government during consideration of the Nocton Dairy application (10/1397/FUL). Furthermore in his consideration of an appeal relating to four buildings at a centre for breeding animals for research at Grimston, Hull, the Inspector stated "I have carefully considered whether the strongly held moral and ethical objections to the proposal are a material consideration in this land use planning decision. The Courts have determined that moral considerations are not normally material to a planning decision... Instead the law currently requires (and has been maintained through the courts on numerous occasions) that decisions must be based on land use related planning considerations, and furthermore that these decisions should be made in accordance with policies set out in the adopted Development Plan. Accordingly, the material planning considerations in this case are considered to be limited to those areas identified above and the wider social, political or ethical issues surrounding animal welfare are not matters that are appropriate to take into consideration... Finally, the potential for the proposed unit to allow for spread of disease between pigs or to humans has also been raised as a reason for concern. It is noted that any person who keeps pigs must by law register the place where they keep them with the Animal and Plan Health Agency (APHA), regardless of numbers. There is then a legal duty to immediately report suspicions that any animal is suffering from a notifiable disease, with failure to do so being an offence under the Animal Health Act 1981. Advice on this can be found within the Code of Practice for the Welfare of Pigs published by the Department for Environment Food and Rural Affairs (DEFRA) on March 1st 2020. Accordingly it is further considered that this is not a material consideration in the determination of this application." (Planning Committee Report-Lafford 2020).

27 Cavan County Council Planning Application 16365.

28 Chief Executive's Order PL96.563.
} 
$[\mathrm{N}]$ ote issues raised in the third party submissions relating to animal welfare and breeches [sic] of DBE regulations. These are not issues that can be assessed in a planning application and the Planning Authority must stay within the remit of proper planning and sustainable development issues such as residential amenities, visual impact, traffic safety, impact on environment, watercourses etc. Issues in relation to animal welfare have been assessed by the Veterinary Officer and will be/are dealt with under the relevant DBE procedures.

The permission was appealed to An Bord Pleanála (“ABP”) by the objectors on a number of grounds, that included objections to the adequacy of the wastewater estimates. The objections were essentially that the wastewater estimates provided by the applicant should not be accepted because the facility could not operate in compliance with welfare laws on the basis of the estimated wastewater output. The objectors' position was that if the facility were to operate in compliance with welfare laws, the wastewater output would be significantly higher, and this would have a bearing on the viability of the planning application submitted. ABP did not substantively consider the impact of animal welfare legislation on the planning application in either the Inspector's report or reference it in its Order.

The Board granted permission. ${ }^{29}$ In respect of the disposal of wastewater the Board required that within 2 months a detailed waste management plan was to be submitted setting out the method of disposal to the Planning Authority for written agreement. Consequently, the plan for disposal of wastewater was not altered from that initially approved by the Planning Authority in Cavan.

\section{The Generation of Wastewater in the Facility in the Cavan Application}

As detailed previously, the generation of wastewater to an extent reflects the levels of hygiene maintained in a DBE. Where a planning authority at the planning stage does not have regard to whether wastewater estimates reflect appropriate practice under Animal Welfare laws, it risks allowing approval of a development that the moment it becomes operational is either in breach of the law, or not fit for purpose. In the Cavan application there were three areas where the applicant had not given consideration to his statutory duties in relation to animal welfare which would have an impact on the wastewater output, these were (1) required activities that would generate wastewater; (2) the frequency of cleans in order to maintain a hygienic establishment; and (3) the amount of water used per clean to ensure the cleaning regime was effective. These commissions were identified by the objectors to the Planning Authority but were disregarded.

\section{(1) Activities generating wastewater}

The applicant set out how much wastewater would be generated from the cleaning of the kennels but neglected to consider other activities that would generate

29 Order PL 02.248325. 
wastewater, and which are required to be carried out under the DBEA and DBEG. Consequently, no allowance was made for wastewater generated by the grooming of dogs, the cleaning of eating and drinking vessels, extra washouts required in the event of illness or washouts required after a bitch has whelped. The difficulty this creates from a planning perspective is that if the DBE is subsequently required to carry out these activities as they would be required to under the DBEG, this could have a substantial impact on the amount of wastewater it generates.

\section{(2) The frequency of cleans}

The applicant proposed to hose down the kennels once every 2 months. The DBEG requires kennels to be cleaned "as appropriate". The applicant did not provide any information to demonstrate the basis on which it was considered that this cleaning regime was appropriate, and this issue was not interrogated by the planning bodies.

There is little guidance issued in the ROI as to what is considered an appropriate cleaning regime. In the United Kingdom the CIEH Model Licence Conditions and Guidance for Dog Breeding Establishments (Chartered Institute of Environmental Health, January 2014) is supported by the Department for Environment and Rural Affairs, Dogs Trust, RSPCA and the British Veterinary Associations amongst other notable bodies. It proposes the following cleaning regime:

- There should be a hose down of exercise areas daily.

- For kennels only housing adult dogs a spot clean should be undertaken daily. A weekly wash down is required using disinfectant; however, the condition of the kennel may require more frequent wash downs.

- Kennels housing litters of puppies require a daily wash down using detergent.

- Kennels housing recently whelped bitches require twice daily cleaning with disinfectant.

It is accepted that every dog breeding facility is different as the layout, construction, operation of the facility as well as the breed and age of the dogs kept will have an impact on the cleaning regimes. For this reason, it can be understood why the Irish legislation is not prescriptive. However, the term "appropriate" must be determined by reference to some established standards and where there is a significant divergence this should be justified by the operator of the DBE. It is acknowledged that the UK model licence conditions are best practice, however it provides a reference point against which to assess a cleaning proposal. ${ }^{30}$ The significant divergence

\footnotetext{
30 It is also worth noting that the Dutch study into the incidence of Enteropathogens in puppies from pet shops and breeding facilities (Dupont and Butaye 2013) found that puppies from pet stores or breeding facilities have a higher risk of gastrointestinal disease. The article noted that "all breeding facilities and pet shops removed the faeces at least twice daily. The breeding facilities were cleaned at least once daily using water or a commercial household product... All the facilities had a history of clinical problems with G. duodenalis..". The discussion went on to state, "All pups, of which the deworming status was known, were dewormed less than a month before sampling. However, half of the sampled population was positive for T. canis ... A plausible explanation is that the hygiene measures are inadequate to avoid reinfection. Indeed the eggs and oocysts of the parasites are very resistant and a correct disinfectant and frequent cleaning are of primary importance to decrease infection pressure...".
} 
in the two approaches raises concerns about the adequacy of the cleaning regime and the applicant's compliance with the animal welfare legislation.

(3) The amount of water used per clean

This issue is closely linked with that discussed above. The amount of water used per clean will have a bearing on how thorough that clean is.

In the Cavan Application the applicant estimated that a washout of each building would use $1000 \mathrm{l}$ of water. There are seven buildings which equates to approximately 70001 of wastewater every 2 months. As noted, the applicant did not provide any information to demonstrate the basis on which it was determined that this amount of water would be adequate to ensure the facilities were kept clean. This estimate must be considered alongside the frequency of the cleans as discussed above.

There is limited information relating to best practice cleaning regimes and the average wastewater output kennel cleaning activities generate. However, information was obtained from a pet healthcare industry source that set out approximate water usage in boarding kennels for the purposes of assessing plumbing requirements. It estimated a clean of kennels with a power house would use approximately 121 of water per dog (Learned 2014). A weekly clean based on this estimate would generate approximately 33,600 1 of wastewater every 2 months. This is 4.8 times that proposed by the applicant.

(4) A comparison-The Dogs Trust rehoming centre

In considering the adequacy of the Applicant's proposals in the whole, it is helpful to consider the waste outputs of another large-scale facility housing dogs. The Dogs Trust's rehoming facility in Fingal County Council, just outside of Dublin, provides a useful comparison. It is accepted that the cleaning protocols and staff to dog ratio are likely to reflect best practice. Nevertheless, the significant divergence in the wastewater output raises further concerns about the overall approach adopted by the applicant in respect of running of the facility and compliance with the animal welfare legislation.

In 2010 Dogs Trust made an application to Fingal County Council for a trade effluent discharge licence in accordance with the Local Government (Water Pollution) Acts 1977 and 1990. Fingal County Council advised that the licence was sought because the facility discharged in excess of 50001 of waste per day. ${ }^{31}$ At this point Dogs Trust were keeping approximately 120 dogs in the centre (Planning Application F06A/1680 2007). It should be noted that these figures would have included waste produced as consequence of activities other than the cleaning of the kennels, but would in large part have been generated by activities to facilitate the wellbeing of the dogs in the rehoming centre. If wastewater were to be generated at the same rate per day, per dog, at the Applicant's facility, the wastewater generated would be approximately 875,0001 every 2 months. ${ }^{32}$ This is 125 times more wastewater than the applicant proposes will be produced.

\footnotetext{
31 Email correspondence between Fingal County Council Water Pollution Officer and the author dated 5 November 2018.

$3250001 / 120$ dogs $* 350$ dogs * 60 days.
} 
If an establishment were required to alter the cleaning regime after the grant of planning permission, there is risk that the infrastructure of the facility would be unable to cope with the increased wastewater production. There runs the very real possibility that the facility approved by the planning bodies will when operating in compliance with the animal welfare laws be unfit for purpose. The creation of such a situation runs counter to the objectives of planning law which is to ensure the appropriate use of the land and the facilitation of sustainable development.

\section{The Disposal of the Wastewater}

The method by which wastewater is disposed is determined by the amount of wastewater and the quality of the wastewater e.g. whether it may contain hazardous substances. The proposed method by which the wastewater in the DBE would be disposed was through irrigation onto farmland. Two issues arise from this practice: (1) this should not be an approved method of disposal irrespective of the cleanliness of the establishment because this wastewater is an inherently hazardous substance; and (2) the risks that this method of disposal pose are potentially exacerbated by the failure to have regard to the animal welfare issues which may increase the likelihood that the waste carries infectious diseases that can be transmitted to both livestock and humans.

\section{Irrigating Farmland with Wastewater from DBEs}

The planning permission requires the irrigation of farmland with wastewater to be carried out in compliance with the EU (Good Agricultural Practice for Protection of Waters) Regulations 2017 ("GAPPW"). GAPPW was implemented to protect waterways from the adverse impact of agricultural activities. The regulations are directed towards the by-products from agriculture.

The authorities failed to consider whether waste from DBEs can be considered "agricultural". In the context of waste management and dogs, it is incorrect to classify the waste as agricultural because the dog is "farmed". This approach overlooks the purpose of the legislation which is to control the environmental harm posed by the waste. It is not clear why the authorities did not consider it necessary to evaluate whether dog waste could be considered "agricultural" waste. Notably there was an objection premised on these grounds, and this was not addressed in any of the planning authorities' reports or decisions.

The issue as to whether dog waste falls within the ambit of the GAPPW is a significant issue as failings in this area can have effects on public health, livestock, and the environment. To unpack why the contention is that dog waste should be distinguished from agricultural by-products, it is helpful to first consider with Directive EC1069/2009 as transposed into Irish law by European Union (Animal By-Products) Regulations 2014 (SI No 187 of 2014). This directive lays downhealth rules concerning animal by-products not intended for human consumption, and specifically considers what animal by-products can be land-spread. Distinctions are drawn 
between the different types of waste because of the harms posed by the by-product. ${ }^{33}$ Article 2(k) sets out that these regulations do not apply to excrement and urine other than "manure". "Manure" is defined as excrement or urine of farmed animals. ${ }^{34}$ The definitions section in Article 3 makes a distinction between "farmed animals" 35 " and "pet animals" 36 ", and therefore the position is that this waste is not an animal byproduct for the purposes of considering whether it can be used in land-spreading, or disposed of in compliance with the GAPPW.

It is appreciated that the definition of "pet" does give rise to some ambiguity in the context of DBEs through the use of the phrase "kept.. but not consumed for purposes other than farming". However, in considering this definition one must have regard to the purpose of the legislation and the overarching Waste Framework Directive which is to reduce the impact of waste on the environment and human health (which is considered earlier in this paper). Further, whilst in the ROI studies have been undertaken into the safety implications of the spreading of waste from farm animals (Food Safety Authority of Ireland 2008), it has not been undertaken in relation to the spreading of waste derived from dogs. ${ }^{37}$ The scientific evidence is that dog faeces is potentially infectious and poses a risk to animal and human health (Namazi 2015; Towsey 2010; Gondim 2004; Lafferty 2002; Deem 2001; Dupont and Butaye 2013). Therefore in the absence of any substantive information to demonstrate that irrigation with wastewater from kennels is an appropriate and safe disposal method from the perspective of the environment and public health, it would be consistent with the objectives of the legislation to prevent this practise. Such an approach would also align with practices in other jurisdictions (Northern Ireland Environment Agency, Scottish Environment Protection Agency, and Natural Resources Wales 2017, pp. 7-10).

\section{The Risks Posed by the Proposed Wastewater Disposal are Exacerbated by the Failure to have Regard to Animal Welfare Laws}

The risks posed to the environment and public health from wastewater from DBEs has been considered. These threats are potentially exacerbated where animal welfare laws are not given consideration at the planning stage. As detailed above, inadequate cleaning regimes can lead to outbreaks of disease amongst dogs. Consequently, it

\footnotetext{
33 Paragraph 8 "Regulation (EC) No 1774/2002 introduced the classification of animal by-products into three categories according to the degree of risk involved" and paragraph 29 "Animal by-products and derived products should be classified into three categories which reflect the degree of risk that they pose to the public and animal health, on the basis of risk assessments".

34 Article 3(20).

35 Article 3(6)(a) any animal that is kept, fattened or bred by humans used for the production of food, wool, fur, feathers, hides and skins or any other products obtained from animals or for other farming purposes.

36 Article 3(8) any animal belonging to a species normally nourished and kept but not consumed, by humans for purposes other than farming.

37 Parliamentary Question 465, 28 March 2017 by Deputy Maureen O’Sullivan.
} 
is more likely that pathogens will be present in the waste that dogs produce. This increases the likelihood of the spread of disease. As some DBEs run in close proximity to, or alongside, farms ${ }^{38}$ there is the risk of these diseases being spread to livestock. Indeed Teagasc (Agriculture Food and Development Authority) in 2015 was promoting dog breeding as a supplemental farming activity (Lillington 2016). This approach risks not only the breach of welfare laws for the animals in the establishment, but it also risks breaching animal welfare laws that are designed to prevent the spread of disease to animals outside the dog breeding facility. Furthermore, there is also the risk that disease could spread to wildlife. This facility fell within the buffer zone $^{39}$ of Natura 2000 site, which is an area of land that has special designation under European law because of the species that inhabit it. ${ }^{40}$ These practices could potentially pose significant risks to indigenous wildlife.

The environmental risks posed by this practise have not been extensively considered. What is known is that dog faeces contains nutrients in different quantities to livestock and is particularly rich in Nitrogen (Patterson 2007). The failure to have regard to animal welfare laws has allowed the planning bodies to proceed on the basis that the wastewater outputs will be relatively low and consequently there has been no consideration of whether discharge licences ${ }^{41}$ are required-such licences would prevent this wastewater from being discharged into the natural environment in this raw state. The irrigation of this wastewater has been allowed without adequate consideration being given to the different nutrient structure of dog faeces. This runs the risk that more Nitrogen is potentially leaching into waterways than is otherwise intended which may threaten the viability of natural water sources.

\section{Conclusion}

The Cavan Application demonstrates the potential problems that could occur where planning applications involving DBEs do not have regard to animal welfare legislation. The case study shows that whilst the health and welfare of animals may not at first glance appear to be a planning consideration, if procedures necessary to maintain health and welfare are not considered then we risk allowing facilities to be built that when operational place our health, economy and environment in jeopardy. As the world grapples with Coronavirus, one of the issues that is emerging is that our management of intensive breeding/farming facilities may need to be reconsidered if we wish to avoid further pandemics (Spinney 2020). In respect of DBEs there is an obvious way to address aspects of this risk and there is a legislative regime that

\footnotetext{
38 An improvement notice issued to Raymond Cullivan provided in condition 5, "The operator must discontinue housing of dogs in close proximity to farm animals. Adequate separation must be provided between dogs and farm animals.".

39 See the report of Peter Radmall appended to the Objector's submissions.

40 This should have been a consideration in respect of whether an Environmental Impact Assessment was required, but it was not. There is potentially a risk here that the EIA Regulations were breached.

${ }^{41}$ Local Government (Water Pollution) Act.
} 
will facilitate it - all that is required is for animal welfare matters to be given proper regard at the planning application stage.

One cannot however ignore the difficulties that this approach may pose from the perspective of advancing the plight of animals in the context of planning. In attempting to further an animal welfare objective, the arguments in this paper have bent to the perceived constraints of the planning process not to have regard to ethical concerns around the confinement of animals. Consequently, the welfare argument has been framed within environmental and public health concerns. This continues to give primacy to social and economic factors, whilst to a large extent ignoring the very serious implications that breeding and agricultural operations can have on the wellbeing of animals within them. Such an approach may entrench the notion that ethical issues around the housing/confinement of animals under planning law is not a valid consideration. For those who wish to advance animal welfare issues within the context of planning law this may be an imperfect way to seek to achieve better conditions for animals at the planning stage. Perhaps the arguments in this paper should not be considered a panacea, but rather one tool that can be used to attempt to address the welfare issues that are ever present during the life of animals kept in confinement for the purposes of human use.

\section{References}

ABC News. 2016. Campaigner calls for overhaul of planning laws to ensure animal welfare in intensive farming. Retrieved March, 2020 from https://www.abc.net.au/news/2016-02-19/campaigner-calls -for-overhaul-of-planning-laws-to-ensure-animal/7182788.

Centre for Food Security and Public Health. 2005. Sarcocystosis. Retrieved February, 2020, from https:// www.cfsph.iastate.edu/Factsheets/pdfs/sarcocystosis.pdf.

Centers for Disease Control and Prevention. 2019. Parasites-Echinococcosis. Retrieved February, 2020, from https://www.cdc.gov/parasites/echinococcosis/biology.html.

Chartered Institute of Environmental Health. 2014. CIEH model licence conditions and guidance for dog breeding establishments. London: Chartered Institute of Environmental Health.

Chislock, M. F., and E. Doster. 2013. Eutrophication: Causes, consequences, and controls in aquatic ecosystems. Retrieved February, 2020, from Nature: https://www.nature.com/scitable/knowledge/ library/eutrophication-causes-consequences-and-controls-in-aquatic-102364466/.

Clarebout, E., and S. Casaert. 2009. Giardia and other intestinal parasites in different dog populations in Northern Belgium. Veterinary Parasitology 161(1): 41-46.

Compassion in World Farming. n.d. How to oppose factory farming proposals. Retrieved February, 15, 2020, from https://www.ciwf.org.uk/our-campaigns/opposing-planning-applications/.

Deem, S. 2001. Putting theory into practice: Wildlife health in conservation. Conservation Biology 15(5): 1224-1233.

Dendoncker, P. A. 2018. Biosecurity and management practices in different dog breeding systems have considerable margins for improvement. Veterinary Record 183(12): 381.

Department of Agriculture Food and the Marine. n.d. Animal by products and you. Retrieved February, 2020, from https://www.agriculture.gov.ie/agri-foodindustry/animalbyproducts/.

Dubey, J.P. 2003. Review of Neospora caninum and neosporosis in animals. The Korean Journal of Parisitology 41(1): 1-16.

Dupont, S., and P. Butaye. 2013. Enteropathogens in pups from pet shops and breeding facilities. Journal of Small Animal Practice 54(9): 475-480.

Environmental Protection Authority. n.d. Protecting Your Private Well. Retrieved May 2020, from https:// www.epa.ie/water/dw/hhinfo/protprivwell/. 
Food Safety Authority of Ireland. 2008. Food safety implications of land-spreading agricultural, municipal and industrial organic materials on agricultural land used for food production in Ireland. Dublin: Food Safety Authority of Ireland.

Gondim, L., M. McAllister, N. Mateus-Pinilla, W. Pitt, L. D. Mech, and M. Nelson. 2004. Transmission of Neospora Caninum between wild and domestic animals. Journal of Parasitology 90: 1361-1365.

Gore-Grimes, J. 2011. Planning and environment law in Ireland. Dublin: Bloomsbury Professional.

Grist, B. 2012. An introduction to Irish planning law. 2nd ed. Dublin: Institute of Public Administration.

Hurt, J. M. 2016. Evaluating the physical welfare of dogs in commercial breeding facilities in the United States. Purdue e-Pubs: Open Access Theses (967).

Lafferty, K. A. 2002. Good medicine for conservation biology: The intersection of epidemiology and conservation theory. Conservation Biology 3(16).

Learned, S. C. 2014. Determining water consumption in animal care facilities. Retrieved February 21, 2020, from DVM360: https:/www.dvm360.com/view/determining-water-consumption-anima 1-care-facilities.

Lillington, K. 2016. Sad realities of our domestic puppy farming industry. The Irish Times.

McMillan, F. 2017. Behavioural and pyschological outcomes for dogs sold as puppies through pet stores and/or born in commerical breeding establishments: Current knowledge and putative causes. Journal of Veterinary Behaviour 19: 14-26.

Mirza, A. 2012. Toxocariasis, hydatid disease of the lung, strongyloidiasis, and pulmonary paragonimiasis. In Kendig \& Chernick's Disorders of the Respiratory Tract in Children, ed. R. Wilmott, 8th edn, 552-563, Saunders.

Namazi, I.G. 2015. Review of bacterial and viral zoonotic infections transmitted by dogs. Journal of Medicine and Life 8(4): 1-5.

Northern Ireland Environment Agency, Scottish Environment Protection Agency, and Natural Resources Wales. 2017. GPP24: Stables, kennels and catteries. Retrieved February, 2020, from https://www. netregs.org.uk/media/1413/gpp-24-final-3.pdf.

Patterson, L.N. 2007. Design, testing and implementation of a large-scale dog waste composting program. Compost Sciene \& Utilization 15(4): 237-242.

Planning Application F06A/1680 (Fingal County Council 2007).

Planning Committee Report - Lafford, 19/1085/FUL (May 15, 2020).

Rego, O. 2017. Animal Welfare and the resource Management Act 1991-Dissertation submitted in partial fulfillment of the degree of Bachelor of Laws (honours). Dunedin: University of Otago.

Spinney, L. 2020. Is factory farming to blame for coronavirus? The Guardian. Retrieved May 5, 2020, from https://www.theguardian.com/world/2020/mar/28/is-factory-farming-to-blame-for-coronaviru s?CMP=share_btn_tw.

Stull, W.J., and J. O'Quin. 2016. Infectious disease in dogs in group settings: strategies to prevent infectious diseases in dogs at dog shows, sporting events, and other canine group settings. Journal of the American Veterinary Medical Association 249(6): 612-627.

Towsey, M. 2010. Something stinks: The need for environmental regulation of puppy mills. Villa Nova Environmental Law Journal 21: 159.

Publisher's Note Springer Nature remains neutral with regard to jurisdictional claims in published maps and institutional affiliations. 